\title{
Gender Identification from Thumbprint Ridge Thickness Among Hausa Population of Nigeria Using Likelihood Ratio and Posterior Probability Density
}

\author{
${ }^{* 1}$ L.H. Adamu, 1,2M.G. Taura and ${ }^{1}$ A.Y. Asuku \\ 1Department of Anatomy, Faculty of Basic Medical Sciences, College of Health Sciences, Bayero University Kano, Nigeria \\ 2Department of Anatomy College of Medicine University of Bisha, Bisha, Kingdom of Saudi Arabia,
} [ ${ }^{\star}$ Corresponding Author: E-mail: alhassan.ana@buk.edu.ng; D: +2348138300444]

\section{ABSTRACT}

The objectives of the present study were to identify gender from thumbprints ridge thickness using likelihood ratio and posterior probability density as well as to determine which of the three areas of thumb has more potential in sex determination. Ridge thickness for 97 male and 97 female subjects within the age range of 18-25 years were examined within the $25 \mathrm{~mm}^{2}$ areas of the ulnar, radial and proximal parts of the thumb making up 1164 areas of the thumbprints. Female subjects exhibited finer ridge count compared to males in ulnar area of both sides of the thumbs. In the radial area, females were found to have finer ridge counts as in ulnar side, but with some coarse ridge. For the right proximal ridge thickness, a similar trend to that in the radial area was noticed, however, in the left thumbprint, males tend to have finer ridge counts compared to females. It was noticed that chance of sex inference from likelihood ratio decreased in the following order: proximal ridge thickness < radial ridge thickness < ulnar ridge thickness as ridge thickness decreases in favor of females but left proximal ridge thickness showed increased in likelihood ratio as ridge thickness decreased in favor of males. Ridge thickness in ulnar area showed more discrimination power compared to the other two areas studied. Considering equal probability for each sex, likelihood ratio reveals the applicability of ridge thickness in sex inference among Hausa population.

Keywords: Forensic sciences, likelihood ratio, Hausa population, ridge thickness, sex inference.

\section{INTRODUCTION}

The true breadth of a ridge is defined as the distance between the centre of one epidermal furrow and the centre of the next furrow along a line at right angles to the direction of the furrows (Penrose, 1968). For printed ridge (line) the term ridge width was suggested to be the more appropriate (Kralik and Novotny, 2003). However, the term epidermal ridge thickness was also used in the same context (Adamu et al., 2016). The pattern and arrangement of epidermal ridges showed remarkable number of features that reflect the biology of human population. These features differ statistically between the sexes, ethnic and age groups across human population (Cummins, 1941; Kralik and Novotny, 2003).

Dermatoglyphs parameters are both affected by genetic and prenatal environment; however, after formation, the arrangement of ridges remains constant throughout life (Holt, 1952; Kralik and Novotny, 2003; Reed et al., 2006). Theoretically, it is possible to use human epidermal ridges of fingerprints for determination of interconnected biological profile of the individual who left the prints (Kralik and Novotny, 2003). This may support the usefulness of the epidermal ridge thickness in the process of personal identification. In addition to the use of fingerprints within the forensic community for many decades, their persistence and biological uniqueness allow them to be used for identification of victims of mass disasters when traditional identification becomes difficult or other anthropometric methods are not feasible (Krishan et al., 2013; Rivalderia et al., 2016).

Previous studies have dealt with features such as minutiae (Stoney and Thornton, 1986; GutierrezRedomero et al., 2007; Reinart, 2014; Adamu et al., 2017), ridge density (Gutierrez-Redomero et al., 2013; Kapoor and Badiye, 2015; Adamu et al., 2016; Rivalderia et al., 2016), epidermal ridge width (Cseplák, 1982; Kamp et al., 1999; Králík et al., 2002) in connection with biological profile 
such as gender and age of an individual. The studies conducted by Adamu et al.(2016) which predicted sex among same population using ridge density and thickness probably is the only study reported among Hausa ethnic group of Kano state, Nigeria. The objectives of the present study were to identify sex from thumbprints ridge thickness using likelihood ratio and posterior probability density as well as to determine which of the three areas of thumb has more potential in sex determination.

\section{MATERIALS AND METHODS}

\section{Study population}

The target study population was Hausa ethnic group of Kano State. The state is one of the most populous states in Nigeria. The urban area comprises six major local government areas (LGAs) and covers about $137 \mathrm{~km}^{2}$ area. The principal inhabitants of the state belong to Hausa ethnic group (Barau, 2007). Using simple random technique, the study population comprises of 97 males and 97 females within the age range of 1825years. A total of 1164 areas (6 areas $\times 194$ participants) thumbprints areas were analyzed for the entire population. Any participants with hand deformity, unclear impression, thumbprint, nonHausa ethnic group of Kano State, Nigeria were excluded from the study. Informed consent was obtained from all participants before their enrolment in the study. Ethical approval was obtained from the ethical committee of Kano state Hospitals Management Board and Ahmadu Bello University, Teaching Hospital, Zaria, Faculty of Medicine (ABUTHZ/HREC/506/2015).

\section{Estimation of epidermal ridge thickness}

Live scanner (digital persona, China) was used to capture thumbprint of each participant. Software (Printanalyse) was designed using the Microsoft visual basic (version 6.0) programming language for capturing and determination of ridge density. Each captured plain thumbprints was saved with the name of digit (thumb), sex of the participants, side of the finger (left or right) and unique code of the participants. The thumbprints were classified into three basic patterns; loops, whorl and arches. Two versions, original and enlarge (at a ratio of 7.74), were captured. The original size was used for scaling purpose and enlarged version was used to determine the ridge density in ulnar, radial and proximal area of the thumbs. For the purpose of ensuring real size measurements, Cummins and Midlo (1943) ink method was adopted to capture the plain thumbprints of 30 randomly selected participants from the 194 study population.

Ridge density was examined within the $25 \mathrm{~mm}^{2}$ of the three areas of the thumb as previously described (Acree, 1999; Gutie'rrez-Redomero et al., 2008; Adamu et al., 2016). The ridge thickness (in $\mathrm{mm}$ ) was estimated indirectly from the obtained ridge density using methods reported in the previous literature (Cummins, 1941; Adamu et al., 2016).

\section{Repeatability and strength of the measurements}

To assess the random error and precision of measurements, two sets of measurements were taken and compared using technical error of measurement (TEM) (Aldridge et al., 2005).

Absolute TEM $=\frac{\sqrt{\Sigma \mathrm{di}^{2}}}{2 \mathrm{n}}$

Where

$\Sigma d^{2}=$ summation of deviations (the difference between the first and second measurements) raised to the second power, $n=$ number of volunteers measured, $i=$ the number of deviations

The absolute TEM was expressed as a percentage as follows:

Relative TEM $=\frac{\text { Absolute } \mathrm{TEM}}{\mathrm{VAV}} \times 100$

Where $\mathrm{VAV}=$ variable average value, which is the arithmetic mean of the two measurements obtained (first and second measurements) from each volunteer for the same variable. This 
procedure was performed for each of the $n$ participants and the $n$ averages obtained were summed up and divided by $n$ (total of number of participants) (Perini et al., 2005). The percentage scores exceeding $10 \%$ were deemed poor (Weinberg et al., 2004). To determine the strength of measurements ( $r)$, intra class correlation (ICC) was determined between the variables. The values for the reliability coefficient ranged from 0 to 1 (Shrout and Fleiss, 1979). Thirty randomly selected participants were selected for the evaluation of measurement error. The interval between the first and second measurements was at least one week. All the measurements were within acceptable level of TEM and reliability coefficient.

\section{Calculation of likelihood ratio and favor odd} The calculated LR gives the strength of support for one of the hypotheses: $C$ or $C^{\prime}$. Posterior probabilities $\mathrm{P}(\mathrm{C} / \mathrm{RT})$ and $\mathrm{P}\left(\mathrm{C}^{\prime} / \mathrm{RT}\right)$ were calculated using Bayes' theorem (Grieve and Dunlop, 1992). Favoured odds for support of the most likely hypothesis for a given ridge thickness $P(R T / C)$ and $P\left(R T / C^{\prime}\right)$ were obtained from information both LR computations and posterior probabilities. The likelihood ratio (LR) was calculated using relative frequency of ridge thickness (RT). The likelihood ratio (LR) was calculated as:

$L R=\frac{\text { probability of observing a given ridge thickness if the donor was male }(C)}{\text { probability of observing a given ridge thickness if the donor was female }\left(\mathrm{C}^{\prime}\right)}=\frac{\mathrm{P}(\mathrm{RT} / \mathrm{C})}{\mathrm{P}\left(\frac{\mathrm{RT}}{\mathrm{C}^{\prime}}\right)}$

Where $\mathrm{RT}=\frac{\text { Frequency of a given } \text { ridge thickness }}{\text { Total frequency of all ridge thickness }}$,

$C$ is the male donor, and $C^{\prime}$ is the female donor, and assuming the equal probability between the sexes $P(C)=P\left(C^{\prime}\right)=0.5$.

The ridge density with likelihood ratio of $>1$ is more likely to be of male origin, for $<1$ is likely to female origin. The favor odd (FO) was calculated as:

$\mathrm{FO}=\frac{\mathrm{P}(\mathrm{RT} / \mathrm{C})}{\mathrm{P}(\mathrm{RT} / \mathrm{C})+\mathrm{P}\left(\mathrm{RT} / \mathrm{C}^{\prime}\right)}$

Frequencies for different types of patterns and mean ridge thickness were also determined.

\section{Statistical Analyses}

The data were expressed using frequency distribution charts. Median was used to report central values of the ridge thickness after the data failed normality test (Shapiro-Wilk test, $\mathrm{P}$
$<0.001$ ). Mann Whitney test was used to test for sex differences in the ridge thickness. The analyses were carried out using SPSS version 20 (IBM Corporation, NY, USA). P $<0.05$ was considered as level of significance.

\section{RESULTS}

Figure 1 shows the frequency distribution of the fingerprint pattern in males and females for both left and right thumbs. In both males and females the loops were the most frequent followed by the whorls and the least was the arches. Males tend to have more whorls in the right thumb, whereas females exhibited more whorls in the left thumb. For arches both sexes have frequency in left thumb, however, females had slightly higher frequency of arches than the males counterpart. 


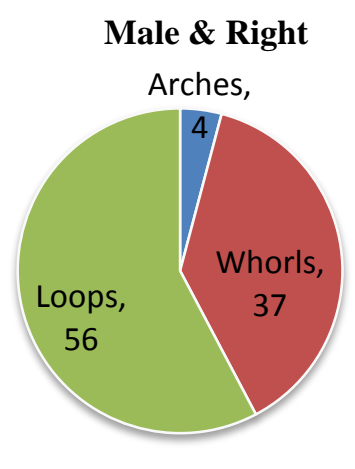

Female \& Right

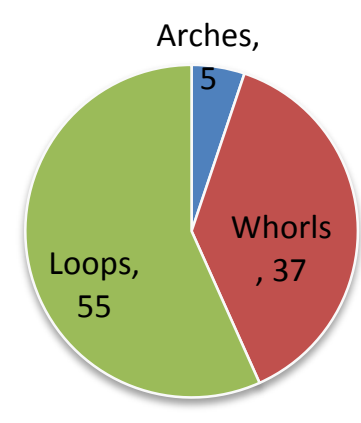

Male \& Left

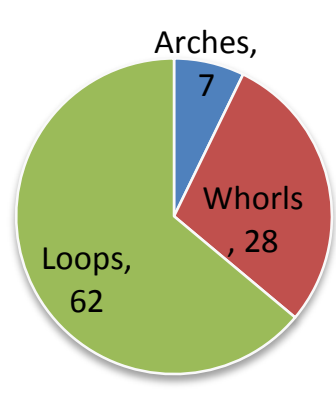

Female \& Left

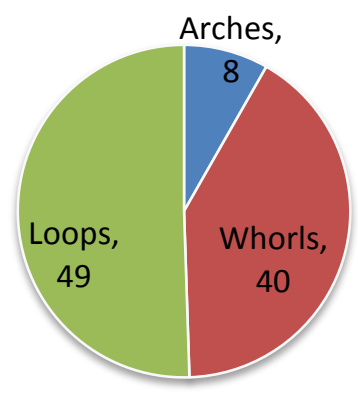

Figure 1: Frequency (\%) of fingerprint patterns according to sex and side of the thumbs of selected subjects among Hausas in Kano State.

Figure 2 shows the differences in ridge thickness in selected subjects. The significant difference was observed only in the right ulnar ridge thickness, where males had thicker ridges. The females were observed to have thicker ridges in the left proximal ridge thickness.

Figure 3 shows the absolute frequency distribution of ridge thickness in males. The ridge thickness was observed to depend on the areas (ulna, radial and proximal) of the fingerprints. The minimum ridge thickness in males was $0.45 \mathrm{~mm}$ and the maximum was $1.06 \mathrm{~mm}$. Wider range of ridge thickness was observed in ulna and radial areas. In the right side the proximal area had higher frequency of thicker ridges $(0.91 \mathrm{~mm})$ whereas in the left the ulna area recorded higher ridge thickness $(1.06 \mathrm{~mm})$. In females (Figure 4) the absolute frequency distribution of ridge density is shown to vary with count areas, with ridge thickness range between $0.45 \mathrm{~mm}$ to 1.27 $\mathrm{mm}$. In all the areas and sides $0.71 \mathrm{~mm}$ ridge thickness is more frequent, although have similar frequency as $0.64 \mathrm{~mm}$ in the left ulna area and $0.80 \mathrm{~mm}$ in the right proximal area of the thumbprints respectively, except for female right ulnar, $0.64 \mathrm{~mm}$ had the highest frequency 
Nigerian Journal of Basic and Applied Science (June, 2018), 26(1): 115-127
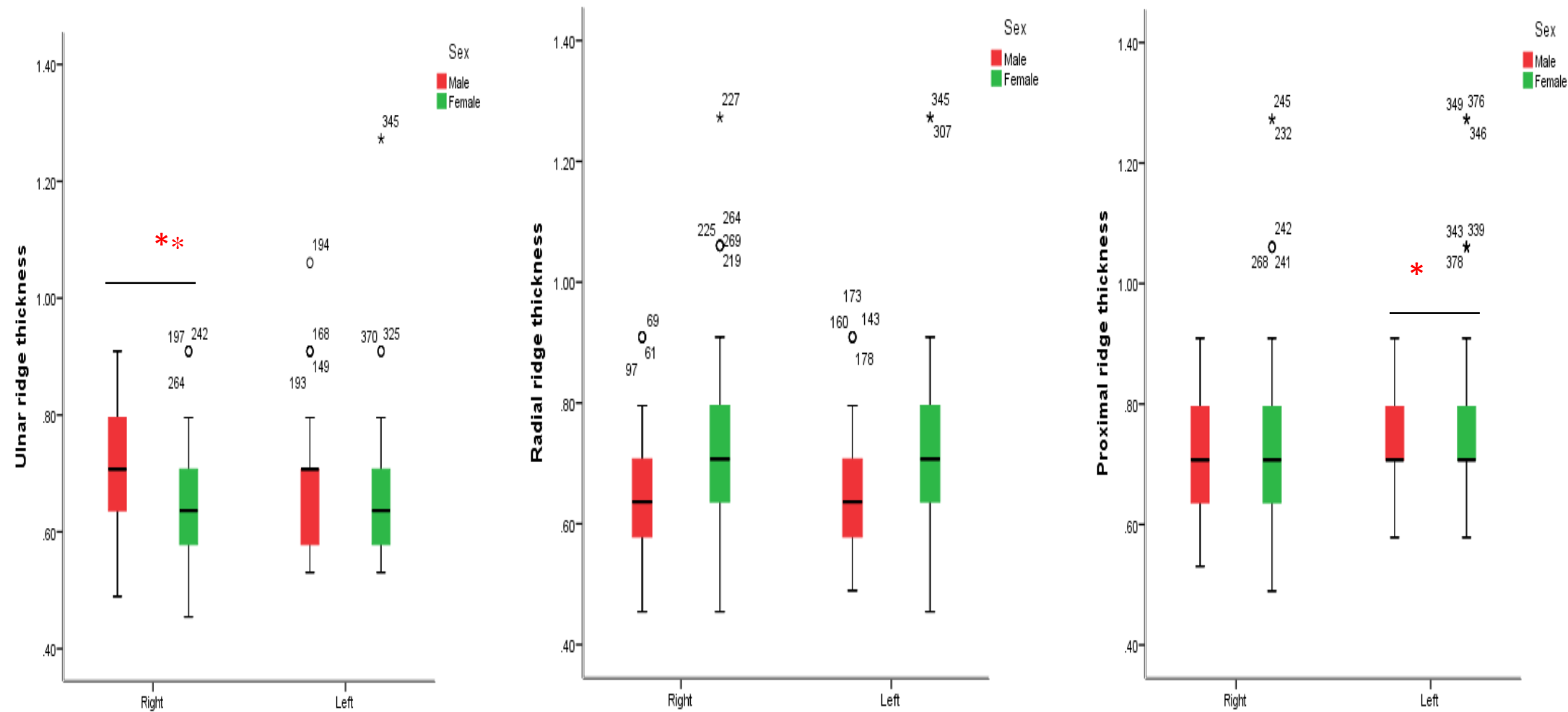

Figure 2: Box and Whiskers showing sex differences in ridge thickness of selected male and female subjects among Hausas in Kano State. The data was represented using box and whiskers plot. Mid-point (black) of the box represents the median; the bottom of the box indicates $25^{\text {th }}$ percentile ( $2^{\text {nd }}$ quartile) and top of the box $75^{\text {th }}$ percentile ( $3^{\text {rd }}$ quartile). The lower and upper limit of the whiskers (T-bars at the bottom and top of the box) represents the minimum to maximum. The dot/asterisk (black) indicates outliers [values that do not fall in the whiskers (1.5 times the height of the box)] and the numbers indicate the serial number of the outliers in the data series ${ }^{* *} P<0.01,{ }^{*} P<0.05$ 


\section{Adamu et al: Gender Identification from Thumbprint Ridge Thickness Among Hausa Population...}

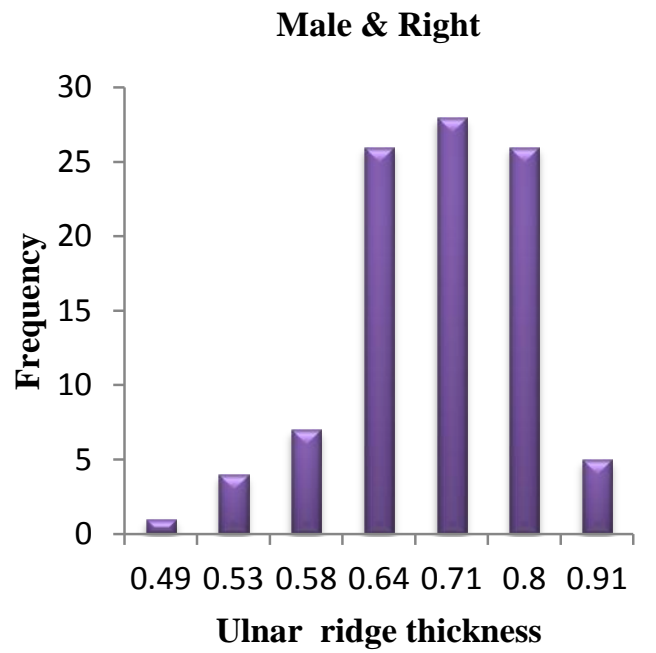

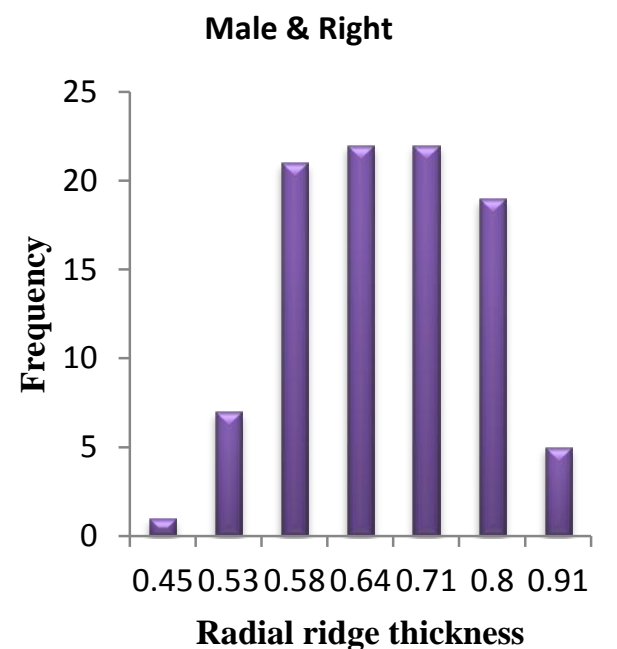

Male \& Left

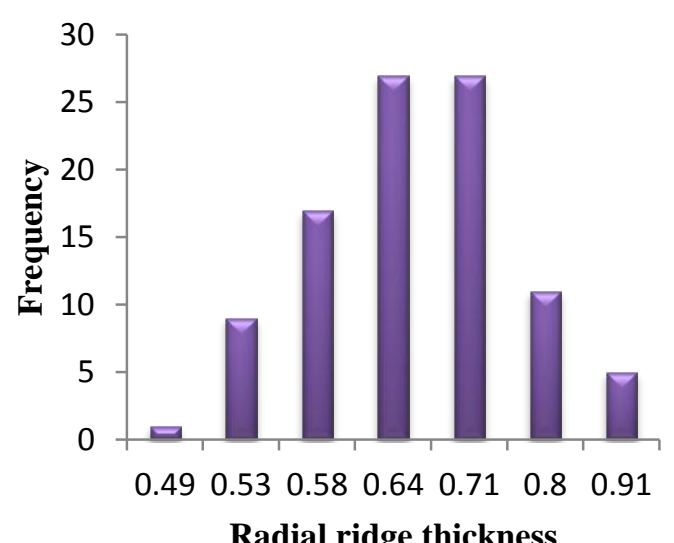

Male \& Right

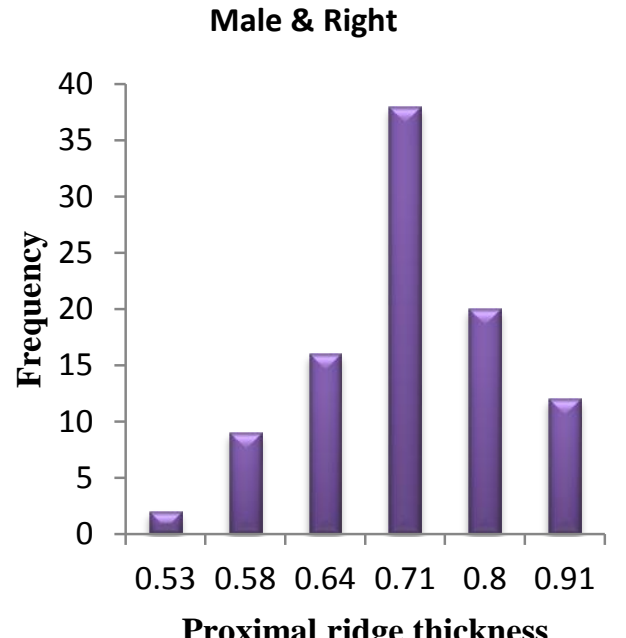

Proximal ridge thickness

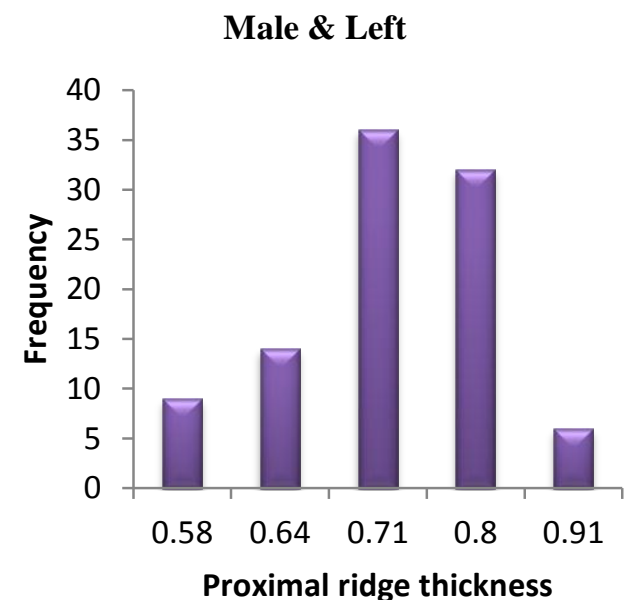

Proximal ridge thickness

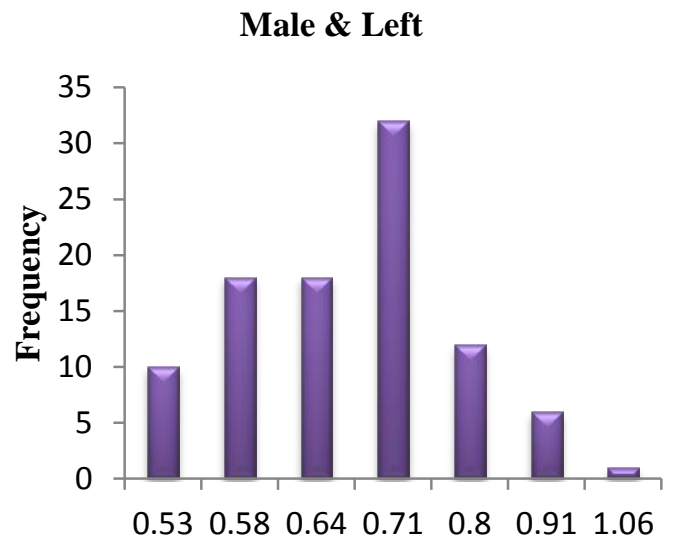

Ulnar ridge thickness

Figure 3: Absolute frequency distribution of thumbprint ridge thickness in selected Hausa males in Kano State 


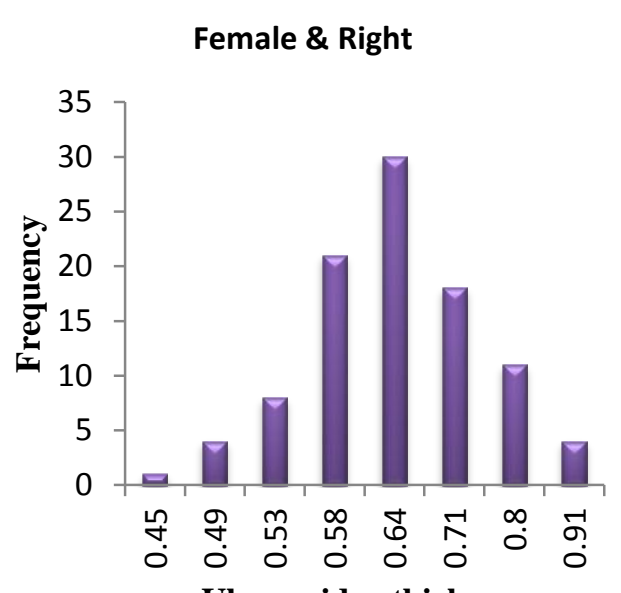

Ulnar ridge thickness

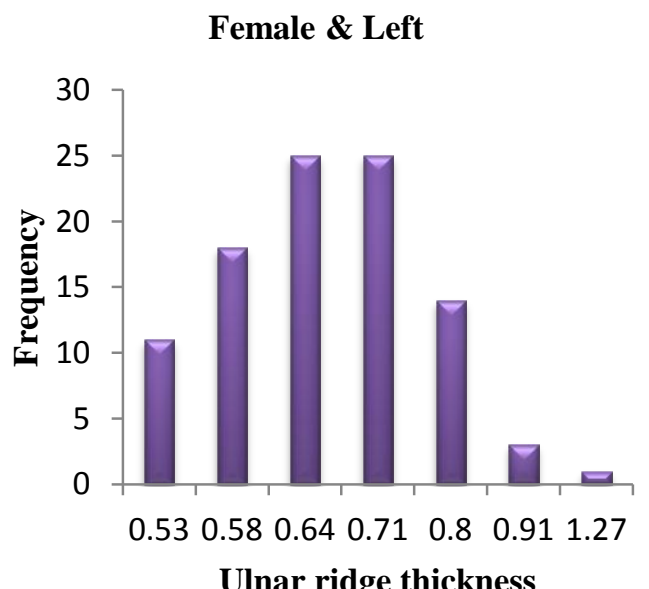

Female \& Right

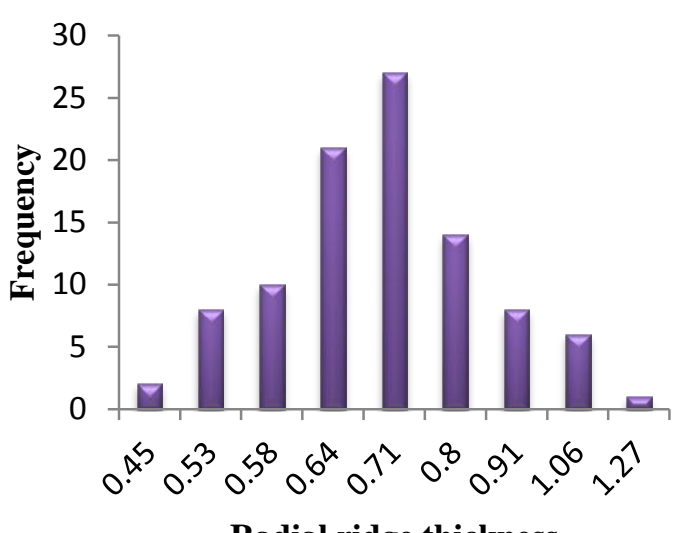

Radial ridge thickness

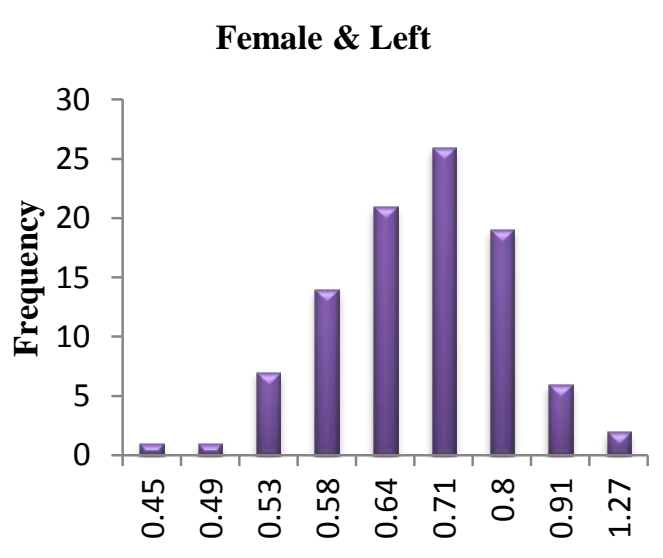

Radial ridge thickness

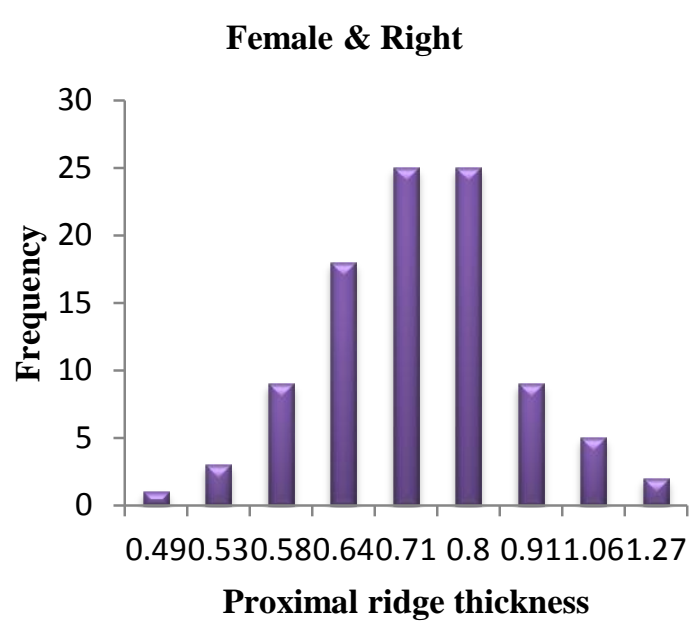

Female \& Left

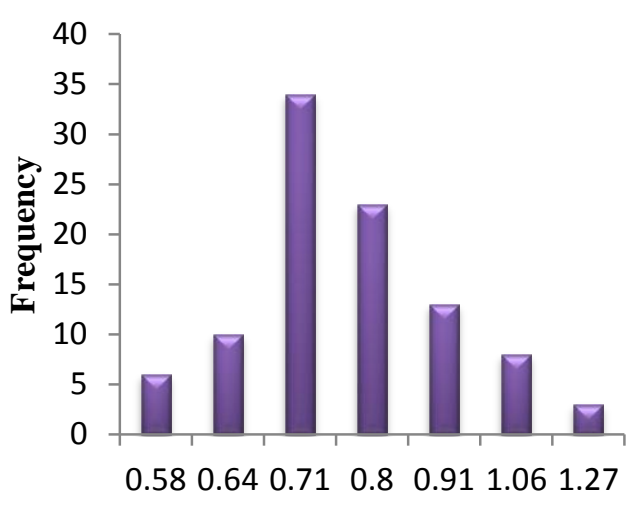

Proximal ridge thickness

Figure 4: Absolute frequency distribution of thumbprint ridge thickness in selected Hausa females in Kano State 
Table 1 shows observed ridge thickness, probability densities, likelihood ratios and favor odds in ulnar area of both left and right thumbs. It was observed that ridge thickness $\geq 0.71 \mathrm{~mm}$ in ulnar area of the right thumb is likely to be of male origin (likelihood ratio $>1$ ). In the ulnar area of the left thumbprint only ridge thickness of 0.71 $\mathrm{mm}$ and $0.91 \mathrm{~mm}$ are likely to be of male origin. In the radial area, the ridge thickness of 0.49-0.71 $\mathrm{mm}$ is most likely to be of male origin and a ridge thickness of $\geq 0.8 \mathrm{~mm}$ is most likely to be of female origin in the left thumbprints (Table 2). From the proximal area of left thumb ridge density of $\geq 0.91$ is most likely to be of female origin and a ridge count of $0.8 \mathrm{~mm}$ or less is most likely to be of female origin (Table 3).

\section{DISCUSSION}

Several parameters are employed for identification purposes, however, fingerprints standout to be the most precise and reliable indicators of sex and personal identity (Arrieta et al., 1990; Esteban and Moral, 1993; Dittmar, 1998; Gutie'rrez-Redomero et al., 2008). Even identical twins who develop from one fertilized egg and share the same DNA profile were reported to have unmatched fingerprints (Cunliffe and Piazza, 1980; Mozayani and Noziglia, 2006).

The frequency of the patterns of the fingerprints among Hausa population of Kano state is in agreement with previous reports in other populations which documented lower and higher frequencies for arch and loop patterns respectively (Galton, 1892; Cummins and Midlo, 1943). The utility of the pattern type of fingerprint may be more to the anthropological perspective than the forensic. Although, comparison of the pattern type where applicable may seem to be an important step for inclusion or exclusion of a suspect in the process of establishment of identity.
The differences in likelihood ratio which was used to infer sex in the present study is in line with sex variation in the epidermal ridge breadth documented earlier (Cummins, 1941; Ohler and Cummins, 1942; Mundorff et al., 2014). The females were observed to have finer ridges except for the proximal ridge thickness which was suggested to exhibit contrasting results of sexual dimorphism with respect to ridge density (Gutie'rrez-Redomero et al., 2008; GutierrezRedomeroa et al., 2011; Adamu et al., 2016; Ahmed and Osman, 2016; Rivalderia et al., 2016). This may further indicate variation of different parts of thumb with proportions of different of the body. Hence, support the fact that different parts of the thumb seem to respond to different developmental instructions, which would be enough justification considering them as an isolated entity (Jantz and Owsley, 1977). Compared to other population (Cummins, 1941), the ridges observed in the current study were thicker. This is in keeping with the previous studies on the ridge density, where Africans, Hausa ethnic group (Adamu et al., 2016) and Sudanese (Ahmed and Osman, 2016) were observed to have lower ridge density compared to Argentinians, Spaniards and central Indians (Gutie'rrez-Redomero et al., 2008; Kapoor and Badiye, 2015; Rivalderia et al., 2016). This led to the suggestion that lower ridge density was more an indicator of African descent (Adamu et al., 2016). The lower ridge density in a given area explains the coarser ridges in this population. However, some of these inter-population variations documented were due to differences in methodological approach of ridge thickness estimation, rather than the expected biological and anthropometric distinction of each population, or developmental differences existing among individuals and populations. Therefore, to draw final conclusion seems to be challenging (Gutierrez-Redomeroa et al., 2011; GutierrezRedomero et al., 2013). 
Table 1: Observed ridge thickness, probability densities, likelihood ratios and favor odds in ulnar area of both left and right thumbs of selected male and female subjects among Hausas in Kano State.

\begin{tabular}{|c|c|c|c|c|c|c|}
\hline \multirow{2}{*}{ Side } & \multirow[b]{2}{*}{ Ulnar } & \multicolumn{2}{|c|}{ Probability distributions } & \multirow{2}{*}{$\begin{array}{l}\text { Likelihood ratio } \\
\mathrm{P}(\mathrm{RD} / \mathrm{C}) / \mathrm{P}\left(\mathrm{RD} / \mathrm{C}^{\prime}\right)\end{array}$} & \multicolumn{2}{|c|}{ Favor Odds } \\
\hline & & $\begin{array}{l}\text { Male } \\
\mathrm{P}(\mathrm{RD} / \mathrm{C})\end{array}$ & $\begin{array}{l}\text { Female } \\
P\left(R D / C^{\prime}\right)\end{array}$ & & Male & Female \\
\hline \multirow[t]{8}{*}{ Right } & 0.45 & 0.00 & 0.02 & 0.00 & 0.00 & 1.00 \\
\hline & 0.49 & 0.02 & 0.08 & 0.25 & 0.20 & 0.80 \\
\hline & 0.53 & 0.08 & 0.16 & 0.50 & 0.33 & 0.67 \\
\hline & 0.58 & 0.14 & 0.43 & 0.33 & 0.25 & 0.75 \\
\hline & 0.64 & 0.54 & 0.62 & 0.87 & 0.46 & 0.54 \\
\hline & 0.71 & 0.58 & 0.37 & 1.56 & 0.61 & 0.39 \\
\hline & 0.80 & 0.54 & 0.23 & 2.36 & 0.70 & 0.30 \\
\hline & 0.91 & 0.10 & 0.08 & 1.25 & 0.56 & 0.44 \\
\hline \multirow[t]{8}{*}{ Left } & 0.53 & 0.21 & 0.23 & 0.91 & 0.48 & 0.52 \\
\hline & 0.58 & 0.37 & 0.37 & 1.00 & 0.50 & 0.50 \\
\hline & 0.64 & 0.37 & 0.52 & 0.72 & 0.42 & 0.58 \\
\hline & 0.71 & 0.66 & 0.52 & 1.28 & 0.56 & 0.44 \\
\hline & 0.8 & 0.25 & 0.29 & 0.86 & 0.46 & 0.54 \\
\hline & 0.91 & 0.12 & 0.06 & 2.00 & 0.67 & 0.33 \\
\hline & 1.06 & 0.02 & 0.00 & - & 1.00 & 0.00 \\
\hline & 1.27 & 0.00 & 0.02 & 0.00 & 0.00 & 1.00 \\
\hline
\end{tabular}

Table 2: Observed ridge thickness, probability densities, likelihood ratios and favor odds in radial area of both left and right thumbs of selected male and female subjects among Hausas in Kano State.

\begin{tabular}{|c|c|c|c|c|c|c|}
\hline \multirow[b]{2}{*}{ Side } & \multirow[b]{2}{*}{ Radial } & \multicolumn{2}{|c|}{ Probability distributions } & \multirow{2}{*}{$\begin{array}{l}\text { Likelihood ratio } \\
\mathrm{P}(\mathrm{RD} / \mathrm{C}) / \mathrm{P}\left(\mathrm{RD} / \mathrm{C}^{\prime}\right)\end{array}$} & \multicolumn{2}{|c|}{ Favor Odds } \\
\hline & & $\begin{array}{l}\text { Male } \\
\text { P(RD/C) }\end{array}$ & $\begin{array}{l}\text { Female } \\
\text { P(RD/C') }\end{array}$ & & Male & Female \\
\hline \multirow[t]{9}{*}{ Right } & 0.45 & 0.02 & 0.04 & 0.50 & 0.33 & 0.67 \\
\hline & 0.53 & 0.14 & 0.16 & 0.88 & 0.47 & 0.53 \\
\hline & 0.58 & 0.43 & 0.21 & 2.10 & 0.68 & 0.32 \\
\hline & 0.64 & 0.45 & 0.43 & 1.05 & 0.51 & 0.49 \\
\hline & 0.71 & 0.45 & 0.56 & 0.81 & 0.45 & 0.55 \\
\hline & 0.8 & 0.39 & 0.29 & 1.36 & 0.58 & 0.42 \\
\hline & 0.91 & 0.10 & 0.16 & 0.63 & 0.38 & 0.62 \\
\hline & 1.06 & 0.00 & 0.12 & 0.00 & 0.00 & 1.00 \\
\hline & 1.27 & 0.00 & 0.02 & 0.00 & 0.00 & 1.00 \\
\hline \multirow[t]{9}{*}{ Left } & 0.45 & 0.00 & 0.02 & 0.00 & 0.00 & 1.00 \\
\hline & 0.49 & 0.02 & 0.02 & 1.00 & 0.50 & 0.50 \\
\hline & 0.53 & 0.19 & 0.14 & 1.29 & 0.56 & 0.44 \\
\hline & 0.58 & 0.35 & 0.29 & 1.21 & 0.55 & 0.45 \\
\hline & 0.64 & 0.56 & 0.43 & 1.29 & 0.56 & 0.44 \\
\hline & 0.71 & 0.56 & 0.54 & 1.04 & 0.51 & 0.49 \\
\hline & 0.8 & 0.23 & 0.39 & 0.58 & 0.37 & 0.63 \\
\hline & 0.91 & 0.10 & 0.12 & 0.83 & 0.45 & 0.55 \\
\hline & 1.27 & 0.00 & 0.04 & 0.00 & 0.00 & 1.00 \\
\hline
\end{tabular}


Adamu et al: Gender Identification from Thumbprint Ridge Thickness Among Hausa Population...

Table 3: Observed ridge thickness, probability densities, likelihood ratios and favor odds in proximal area of both left and right thumbs of selected male and female subjects among Hausas in Kano State.

\begin{tabular}{lcccccc}
\hline & & \multicolumn{2}{c}{ Probability distributions } & Likelihood ratio & \multicolumn{2}{c}{ Favor Odds } \\
\cline { 3 - 4 } Side & Proximal & $\begin{array}{c}\text { Male } \\
\text { P(RD/C) }\end{array}$ & $\begin{array}{c}\text { Female } \\
\text { P(RD/C') }\end{array}$ & P(RD/C)/P(RD/C') & Male & Female \\
\hline Right & 0.49 & 0.00 & 0.02 & 0.00 & 0.00 & 1.00 \\
& 0.53 & 0.04 & 0.06 & 0.67 & 0.40 & 0.60 \\
& 0.58 & 0.19 & 0.19 & 1.00 & 0.50 & 0.50 \\
& 0.64 & 0.33 & 0.37 & 0.89 & 0.47 & 0.53 \\
& 0.71 & 0.78 & 0.52 & 1.52 & 0.60 & 0.40 \\
& 0.8 & 0.41 & 0.52 & 0.80 & 0.44 & 0.56 \\
& 0.91 & 0.25 & 0.19 & 1.33 & 0.57 & 0.43 \\
& 1.06 & 0.00 & 0.10 & 0.00 & 0.00 & 1.00 \\
& 1.27 & 0.00 & 0.04 & 0.00 & 0.00 & 1.00 \\
& 0.58 & 0.19 & 0.12 & 1.50 & 0.60 & 0.40 \\
& 0.64 & 0.29 & 0.21 & 1.40 & 0.58 & 0.42 \\
& 0.71 & 0.74 & 0.70 & 1.06 & 0.51 & 0.49 \\
& 0.8 & 0.66 & 0.47 & 1.39 & 0.58 & 0.42 \\
& 0.91 & 0.12 & 0.27 & 0.46 & 0.32 & 0.68 \\
& 1.06 & 0.00 & 0.16 & 0.00 & 0.00 & 1.00 \\
& 1.27 & 0.00 & 0.06 & 0.00 & 0.00 & 1.00 \\
\hline
\end{tabular}

Sex inference using likelihood ratio may indicate more significant differences between genders that may be used to infer sex better than that which can be obtained using other inferential statistic (Reinart, 2014). It was also suggested that the inferential statistics such as the independent sample analyses may be influenced by the degree of freedom which has little or no influence on the likelihood ratio. In likelihood ratio analyses each ridge thickness is treated as a separate entity, therefore the outliers were used separately in the sex inference. Furthermore, it was demonstrated that racial discrimination that depends on descriptive statistics within the domain of dermatoglyphic and larger community of forensic sciences need to be avoided. More to this, in DNA analyses likelihood ratios are calculated using probabilities based on race (Budowle et al., 1999; Reinart, 2014). However, the use of likelihood ratio depends on the set prior probability, which means that different ratio will be obtained with adjustment of the prior probability. Although given equal chance to the independent groups seems to eliminate bias in making judgments. With regards to both sexes with two independent groups (male and female), it was suggested that if males are more likely to commit a crime, prior probabilities should be set at a higher value in favor of males (GutierrezRedomero, 2013). The use of equal prior probability may still hold more weight as the shift may occur in committing crime with respect to independent group in question.

Significant variations in the epidermal ridge breadth in different dermatoglyphic regions were reported in the previous studies (Cummins, 1941; Ohler and Cummins, 1942). It is therefore important to note that the application of the present study may be more accurate with regards to thumbprints. However, it was suggested that the thumb is as good as the other four digits in most of the handy active due to its complementary role to other digits in object manipulation (Adamu et al., 2016). It is therefore more often encountered in the criminal scene 


\section{Nigerian Journal of Basic and Applied Science (June, 2018), 26(1): 115-127}

than any other digit (Gutierrez-Redomero et al., 2008).

The application of the current study in the field of forensic sciences and by law enforcement agents can be justified especially when dealing with partial fingerprints where all other details such as pattern type and minutiae cannot be appreciated. To emphasize on the application, it is already documented that the ridge density or partial fingerprint of a latent print found at the scene of a crime investigation should be a useful evidence to infer the sex of the perpetrator. This will go in line to help the forensic expert to narrow down the processes of investigation towards suspects belonging to the most likely sex, thereby, reducing the time and effort spent on each case (Gutierrez-Redomeroa et al., 2011). In the context of extrapolation of scientific research into real world scenario it should be remembered that this study used indirect methods of fingerprint ridge thickness determination. Using the method employed in this study atleast three ridges are needed to obtain the thickness of the prints, which is defined as the distance between the center of one epidermal furrow and the center of the next furrow along a line at right angles to the direction of the furrows (Penrose, 1968). Therefore, the partial fingerprint with not more than two ridges may seem to poise some level of inaccuracy in indirect methods of ridge thickness estimation.

\section{CONCLUSION}

Considering equal probability for each sex, likelihood ratio reveals the applicability of ridge thickness in sex inference among Hausa population. Ridge thickness in ulnar area showed more discrimination power compared to the other two areas. The use of likelihood ratio in sex identification from thumbprint ridge thickness proves a useful approach in gender identification among Hausa population of Nigeria

\section{REFERENCES}

Acree, M. A. (1999). Is there a gender difference in fingerprint ridge density? Forensic Science International, 102:35-44.

Adamu, L. H., Ojo, S. A., Danborno, B., Adebisi, S. S. and Taura M. G. (2017). Sex variation in thumbprint minutiae among Hausa lineage. Journal of Anatomical Sciences, 8(1): 39-47

Adamu, L. H., Ojo, S. A., Danborno, B., Adebisi, S. S. and Taura M. G (2016) Sex discrimination using ridge density and thickness among Hausa ethnic groups of Kano state, Nigeria, Australian Journal of Forensic Sciences, 50(5):1-18.

Ahmed, A. A. and Osman, S. (2016). Topological variability and sex differences in fingerprint ridge density in a sample of the Sudanese population. Journal of Forensic Legal Medicine, 42:25-32.

Aldridge, K., Boyadjiev, S. A., Capone, G. T., DeLeon, V. B. and Richtsmeier, J. T. (2005). Precision and error of three dimensional phenotypic measures acquired from $3 \mathrm{dMD}$ photogrammetric images. American Journal of Medical Genetics, 138A: 247-253.

Arrieta, M. I., Martinez, B., Simon, A., Salazar, L., Criado, B. and Lostao, C. M. (1990) Quantitative and qualitative finger dermatoglyphics in the Basque Valley of Urola, Spain. Anthropologischer Anzeiger, 48:65-84.

Barau, A.S. (2007). The great attractions of Kano. Kano: Research and Documentation publications. Research and Documentation Directorate, Government House Kano; ISBN 978-8109-33-0.

Budowle, B., Moretti, T., Baumstark, A., Defenbaugh, D. and Keys K. (1999). Population data on the thirteen CODIS core short tandem repeat loci in African Americans, U.S. Caucasians, Hispanics, Bahamians, Jamacians, and Trinidadians. Journal of Forensic Sciences, 44(6):12771286. 
Cseplák, G. (1982). Anthropological analysis of the impressions originating from man's hand on the neolithic pottery fragments. Humanbiologia Budapestiensis, 10:135140.

Cummins, H. (1941). Ancient finger prints in clay. Science Monitor, 52: 389-402.

Cummins, H. and Midlo, C. (1943). Finger prints, palms and soles. Philadelphia, PA: Blakiston.

Cunliffe, F. and Piazza, P. B. (1980). Criminalistics and scientific investigation. New Jersey: Prentice-Hall, Inc.; 266.

Dittmar, M. (1998). Finger ridge-count asymmetry and diversity in Andean Indians and interpopulation comparisons. American Journal of Physical Anthropology, 105:377-93.

Esteban, E. and Moral, P. (1993). Finger dermatoglyphics in a Mediterranean population (Murcia, Spain): pattern types and pattern intensity index. Anthropologischer Anzeiger 51:159-67.

Galton, F. (1892). Finger prints. London: Mac Millan.

Grieve, M. C. and Dunlop, J. (1992). A practical aspect of the Bayesian interpretation of fibre evidence, Journal of Forensic Sciences Society, 32: 169-175.

Gutie'rrez-Redomero, E., Alonso, C., Romero, E. and Galera, V. (2008). Variability of fingerprint ridge density in a sample of Spanish Caucasians and its application to sex determination. Forensic Science International, 180:17-22.

Gutierrez-Redomero, E., Galera, V., Martınez, J. M. and Alonso, C. (2007). Biological variability of the minutiae in the fingerprints of a sample of the Spanish population. Forensic Science International, 172: 98-105.

Gutierrez-Redomero, E., Sanchez-Andres, A., Rivalderia, N., Alonso-Rodriguez, C., Dipierri, J. E. and Martin, L. M. (2013). A comparative study of topological and sex differences in fingerprint ridge density in Argentinian and Spanish population samples. Journal of Forensic and Legal Medicine, 20:419-429

Gutierrez-Redomeroa, E., Alonso, M. C. and Dipierri, J. E. (2011). Sex differences in fingerprint ridge density in the MatacoMataguayo population. HOMO Journal of Comparative Human Biology, 62: 487499.

Holt, S. (1952). Genetics of Dermal Ridges: Inheritance of total finger ridge-count. Annals of Eugenics, 17:140-161

Jantz, R. L. and Owsley, D. W. (1977). Factor analysis of finger ridge-counts in Blacks and Whites. Annals of Human Biology, 4:357-366.

Kamp, K. A., Timmerman, N., Lind, G., Graybill, J. and Natowsky, I. (1999). Discovering childhood: using fingerprints to find children in the archaeological record. American Antiques, 64: 309-315.

Kapoor, N. and Badiye, A. (2015). Sex differences in thumbprint ridge density in a central Indian population. Egyptian Journal of Forensic Science, 5(1):23-29.

Kralik, M., and Novotny, V. (2003). Epidermal ridge breadth: an indicator of age and sex in paleodermatoglyphics. Variability and Evolution, 11:5-30.

Králík, M., Novotný, V. and Oliva, M. (2002). Fingerprint on the Venus of Dolni Věstonice I. Anthropology (Brno), 40: 107-113.

Krishan, K., Kanchan, T. and Ngangom, C. (2013). A study of sex differences in fingerprint ridge density in a North Indian young adult population. Journal of Forensic and Legal Medicine, 20: 217e22.

Mozayani, A. and Noziglia, C. (2006). The laboratory handbook - procedures and practice. 1st ed. Totowa, New Jersey: Humana Press, p. 123.

Mundorff, A.Z., Bartelink, E.J. and Murad, T.A. (2014). Sexual dimorphism in finger ridge breadth measurements: a tool for sex estimation from fingerprints. Journal of Forensic Sciences, 59: 891-897. 
Ohler, E. A. and Cummins, H. (1942). Sexual differences in breadths of epidermal ridges on finger tips and palms. American Journal of Physical Anthropology, 29: 341-362.

Penrose, L. S. (1968). Memorandum on Dermatoglyphic Nomenclature. Birth Defects Orig Article Series, 4: 1-13.

Perini, T. A., Oliveira1, G. L., Ornellas, J. S., de Oliveira, F. P. (2005). Technical error of measurement in anthropometry. Brazilian Journal of Sports Medicine, 11 (1):86-90.

Reed, T., Viken, R. J. and Rinehart, S. A (2006) High heritability of fingertip arch patterns in twin-pairs, American Journal of Medical Genetics, 140 (3): 263-271.

Reinart, L.F. (2014). Investigating sex differences in fingerprint minutiae density of the core region utilizing the minutiae:ridge-length ratio. Thesis; Master of Science, Boston University.

http://hdl.handle.net/2144/15325
Rivalderia, N., Sanchez-Andres, A., AlonsoRodriguez, C., Dipierri, J. E. and Gutierrez-Redomero, E. (2016). Fingerprint ridge density in the Argentinean population and its application to sex inference: a comparative study. HOMO Journal of Comparative Human Biology, 67:65-84.

Shrout, P. and Fleiss, J. (1979). Intraclass correlations: Uses in assessing rater reliability. Psychology Bulletin, 86: 420428. doi:10.1037/0033-2909.86.2.4202.8.

Stoney, D. A. and Thornton, J. I. (1986). A method for the description of minutia pairs in epidermal ridge patterns. Journal of Forensic Sciences, 31(4):1217-1234

Weinberg, S. M., Scott, N. M., Neiswanger, K., Brandon, C. A. and Marazita, M. L. (2004). Digital three-dimensional photogrammetry: evaluation of anthropometric precision and accuracy using a genex 3D camera system. Cleft Palate Craniofacial Journal, 41(5): 507-518. 